\author{
CZASOPISMO INŻYNIERII LACDOWEJ, ŚRODOWISKA I ARCHITEKTURY \\ JOURNAL OF CIVIL ENGINEERING, ENVIRONMENT AND ARCHITECTURE
}

JCEEA, t. XXXII, z. 62 (3/I/15), lipiec-wrzesień 2015, s. 263-270

\author{
Marcin LEŚKO ${ }^{1}$ \\ Henryk WACHTA ${ }^{2}$ \\ Krzysztof BARAN ${ }^{3}$
}

\title{
ADAPTACYJNE SYSTEMY OŚWIETLENIOWE W TECHNOLOGII LED W ZASTOSOWANIACH PRZEMYSLOWYCH
}

\begin{abstract}
W obiektach przemysłowych, jak hale produkcyjne, rola oświetlenia jest szczególnie ważna dla zapewnienia właściwych warunków pracy wzrokowej. W dużych halach, gdzie występują znacznej wielkości powierzchnie przeszklone w celu wykorzystania światła naturalnego, pojawia się problem współpracy oświetlenia sztucznego i dziennego, objawiający się nierównomiernym rozkładem izoluksów w strefach przyokiennych. W artykule przedstawiono praktyczną realizację adaptacyjnego systemu oświetlenia $\mathrm{z}$ wykorzystaniem lamp w technologii LED oraz systemu DALI (Digital Addressable Lighting Interface) na przykładzie hali produkcyjnej oraz analizę korzyści wynikających z przedstawionego rozwiązania. Jest to system przeznaczony do dynamicznego sterowania oświetleniem w obiektach przemysłowych, biurowych i innych, w których konieczna jest regulacja poziomu natężenia oświetlenia w zależności od warunków oświetlenia dziennego, czy też wyodrębnienie wśród lamp różnych stref użytkowych. W prezentowanym przykładzie modernizacji instalacji oświetleniowej zastąpiono 720 lamp rtęciowych przez 192 lampy typu LED. Spowodowało to poprawę warunków oświetleniowych oraz ograniczenie zużycia energii pobieranej przez źródła światła. Uzyskano możliwość wyrównania rozkładu natężenia oświetlenia $w$ strefach przyokiennych. Przedstawiony w artykule adaptacyjny system sterowania oświetleniem wykorzystujący wydajne oprawy w technologii LED oraz dostosowujący poziom natężenia oświetlenia do warunków oświetlenia dziennego jest nowoczesnym rozwiązaniem, które pozwala na znaczne ograniczenie zużycia energii, a przez to zmniejszenie kosztów eksploatacji instalacji oświetleniowej, co jest istotne w obiektach przemysłowych, ze względu na ilość pracujących opraw.
\end{abstract}

Słowa kluczowe: oświetlenie adaptacyjne, lampa LED, system DALI, efektywność energetyczna

\footnotetext{
${ }^{1}$ Marcin Leśko, Politechnika Rzeszowska, al. Wincentego Pola 2, 35-959 Rzeszów, tel. 17 8652434, mlesko@prz.edu.pl

2 Autor do korespondencji/corresponding author: Henryk Wachta, Politechnika Rzeszowska, al. Wincentego Pola 2, 35-959 Rzeszów, tel. 17 8652434, hwachta@prz.edu.pl

${ }^{3}$ Krzysztof Baran, Politechnika Rzeszowska, , al. Wincentego Pola 2, 35-959 Rzeszów, tel. 17 8652434, kbaran@prz.edu.pl
} 


\section{Wstęp}

Oświetlenie elektryczne jest istotnym elementem w każdym obiekcie budowlanym. W obiektach przemysłowych, jak hale produkcyjne, rola oświetlenia jest szczególnie ważna dla zapewnienia właściwych warunków pracy wzrokowej.

W dużych halach, gdzie występują znacznej wielkości powierzchnie przeszklone w celu wykorzystania światła naturalnego, pojawia się problem współpracy oświetlenia sztucznego i dziennego, objawiający się nierównomiernym rozkładem izoluksów.

W strefach przyokiennych płaszczyzna pracy wzrokowej jest oświetlona w sposób niejednorodny, jednocześnie przy zmiennych warunkach pogodowych (zachmurzenie) zmieniają się warunki oświetleniowe, co przekłada się na pewien dyskomfort pracy wzrokowej przy zastosowaniu konwencjonalnego oświetlenia.

Rozwiązaniem tego problemu jest wykorzystanie adaptacyjnych systemów oświetleniowych, dostosowujących poziom natężenia oświetlenia we wnętrzu w zależności od warunków zewnętrznych, co przekłada się na zapewnienie lepszych warunków oświetleniowych i jednocześnie pozwala zmniejszyć zapotrzebowanie na energię elektryczną. W artykule przedstawiono praktyczną realizację adaptacyjnego systemu oświetlenia z wykorzystaniem lamp w technologii LED oraz systemu DALI (Digital Addressable Lighting Interface) na przykładzie hali produkcyjnej oraz analizę korzyści wynikających z przedstawionego rozwiązania.

\section{Struktura układu sterowania}

System sterowania oświetleniem DALI powstał jako wspólny projekt kilku firm oświetleniowych $[2,8,9]$. Obecnie wiele firm produkuje urządzenia zgodne z tym protokołem komunikacyjnym, który umożliwia współpracę podzespołów różnych producentów. Jest to system przeznaczony do dynamicznego sterowania oświetleniem w obiektach przemysłowych, biurowych i innych, w których konieczna jest regulacja poziomu natężenia oświetlenia w zależności od warunków oświetlenia dziennego, czy też wyodrębnienie wśród lamp różnych stref użytkowych.

Schemat ideowy adaptacyjnego systemu oświetleniowego przedstawiono na rys. 1. 


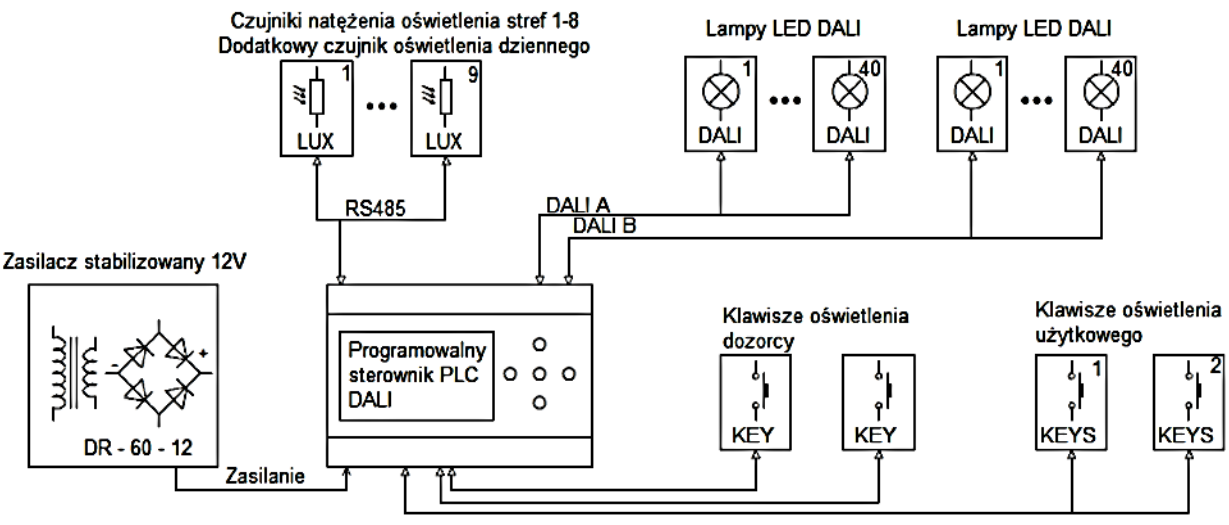

Rys. 1. Schemat ideowy systemu oświetleniowego, opracowano na podstawie [6]

Fig. 1. Schematic diagram of lighting system, on the basis of [6]

Głównym elementem układu jest programowalny sterownik PLC DALI wraz z modułem zasilającym. Sterownik umieszczony jest w szafie rozdzielczej, gdzie doprowadzone są przewody od urządzeń peryferyjnych, które można podzielić na trzy grupy: moduły klawiszowe, oprawy LED zgodne z protokołem DALI oraz czujniki natężenia oświetlenia dla poszczególnych stref sterowania i dodatkowy czujnik oświetlenia dziennego.

System umożliwia sterowanie pojedynczymi oprawami oświetleniowymi, bądź grupami opraw. Każda grupa sterowania posiada czujnik natężenia oświetlenia, korygujący zadaną wartość. Zastosowanie czujnika oświetlenia dziennego pozwala na dostosowanie natężenia oświetlenia w zależności od warunków atmosferycznych (nasłonecznienie, zachmurzenie).

\section{Charakterystyka urządzeń składowych}

Adaptacyjny system sterowania oświetleniem został zbudowany w oparciu o podzespoły zgodne z protokołem DALI, takie, jak:

- jednostka sterująca BS-ST-DIN-DALI,

- moduły klawiszowe BS-KEY-8,

- sensory natężenia oświetlenia BS -LUX -1,

- lampy LED ILO3M100E12PW.

Parametry jednostki sterującej przedstawia tabela 1 . Jest to programowalny sterownik PLC, zapewniający komunikację z lampami za pomocą protokołu DALI oraz z czujnikami natężenia oświetlenia i modułami klawiszowymi. 
Tabela 1. Dane techniczne jednostki sterującej, opracowano na podstawie [6]

Table 1. Technical data of control unit, on the basis of [6]

\begin{tabular}{|c|c|}
\hline Nazwa parametru & Wartość \\
\hline Wymiary przekroju & $90 / 53 / 45 / 63 \mathrm{~mm}$ rys. 1 \\
\hline Szerokość & $120 \mathrm{~mm}$ \\
\hline Pobór mocy & Max 6W \\
\hline Napięcie zasilania & Max 12V DC \\
\hline Przekrój przewodów & RS485 \\
\hline Komunikacja z czujnikami & $38400 \mathrm{bps} 1$ bstart 1bstop \\
\hline Parametry transmisji & DALI / DMX512 \\
\hline Komunikacja z lampami & C/C++ \\
\hline Programowanie sterownika & LCD 128/64 + klawisze nawigacyjne \\
\hline Interfejs użytkownika &
\end{tabular}

Moduły klawiszowe BS-KEY-8 umożliwiają zdalne załączanie wybranych grup opraw oświetleniowych (rys. 2a) oraz wybór trybu pracy: adaptacyjny lub maksymalna moc. Czujniki oświetlenia (rys. 2b) umieszczane są pod sufitem w danych strefach oświetleniowych, a czujnik światła dziennego na zewnątrz obiektu, wykorzystują protokół komunikacyjny RS485.

a)

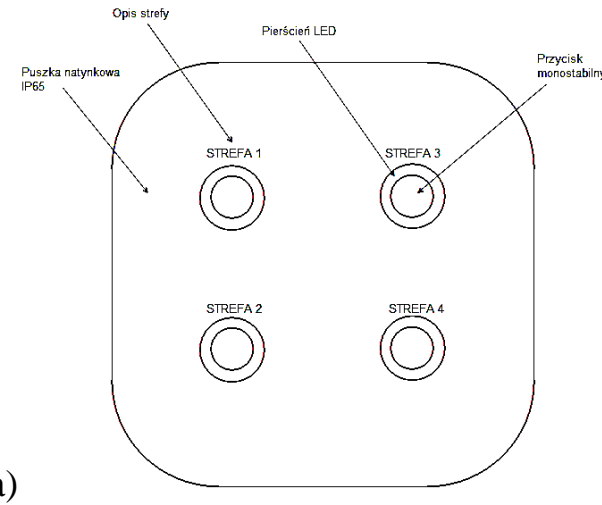

b)

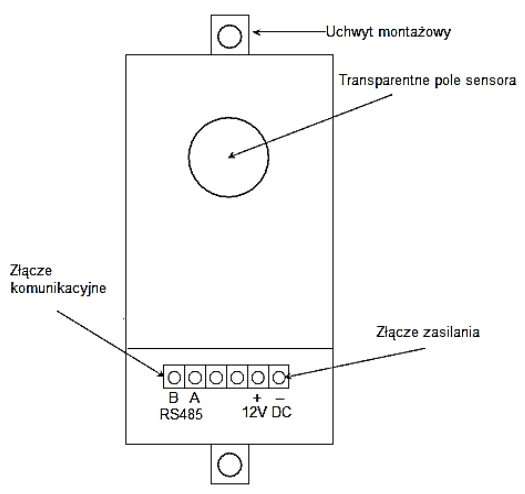

Rys. 2. a) Moduł klawiszowy, b) czujnik natężenia oświetlenia, opracowano na podstawie [6]

Fig. 2. a) Key module, b) illuminance sensor, on the basis of [6]

W skład systemu oświetleniowego wchodzą oprawy LED typu ILO3M100E12PW (rys. 3a), zapewniające możliwość regulacji strumienia świetlnego i pełną zgodność z systemem DALI. Są to oprawy typu highbay o szerokim, obrotowo symetrycznym rozsyle światłości (rys. 3b), co w zestawieniu z dużym strumieniem świetlnym rzędu $12000 \mathrm{~lm}$ pozwala na uzyskanie odpowiednich warunków oświetleniowych i minimalizację liczby opraw. 
a)
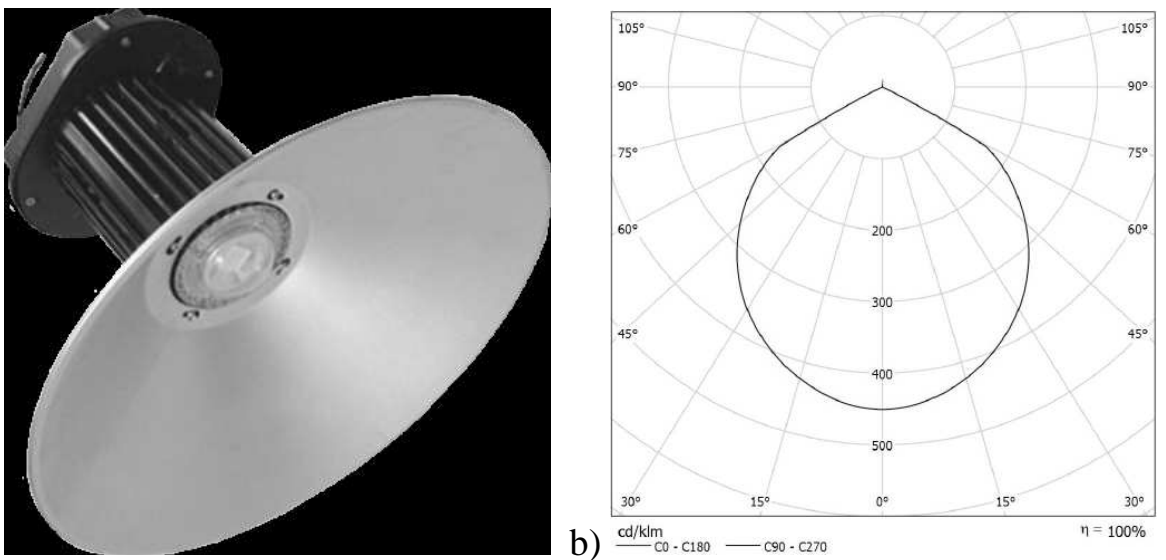

Rys. 3. Oprawa LED ILO3M100E12PW: a) widok oprawy, b) krzywa rozsyłu światłości [3]

Fig. 3. Luminaire LED ILO3M100E12PW: a) luminaire view, b) light distribution curve [3]

\section{Realizacja praktyczna}

Prezentowany przykład realizacji adaptacyjnego systemu oświetleniowego dotyczy modernizacji oświetlenia hali produkcyjnej. System został zainstalowany w jednej z hal Huty Stalowa Wola o wymiarach: $108 \mathrm{~m}$ długości, $48 \mathrm{~m}$ szerokości i 9 m wysokości, przedstawionej na rys. 4.

a)
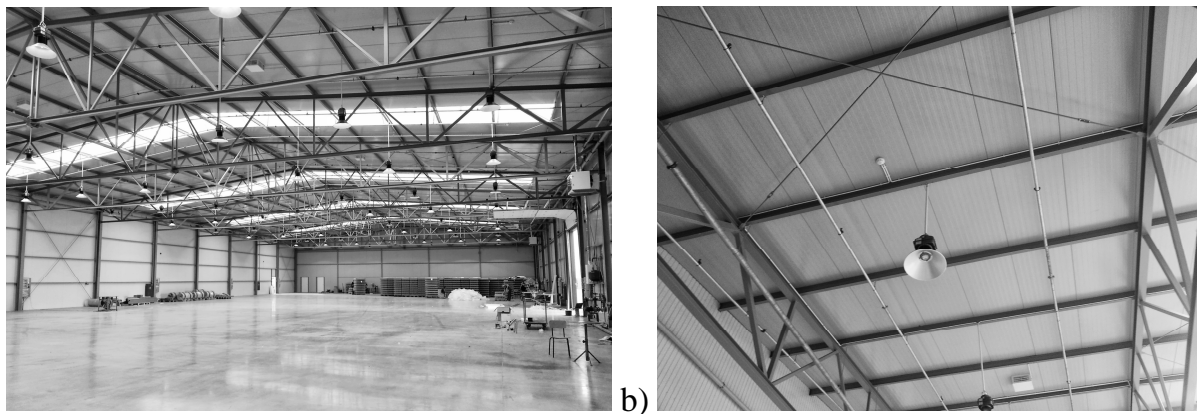

Rys. 4. Widok oświetlanego obiektu: a) hala, b) oprawa [7]

Fig. 4. A view of illuminated object: a) hall, b) luminaire [7]

Omawiany obiekt przed modernizacją oświetlony był za pomocą lamp rtęciowych. Rozwiązanie takie nie było energooszczędne i zapewniało przeciętne warunki oświetleniowe. W hali zainstalowanych było 720 opraw o mocy $400 \mathrm{~W}$ każda, co dawało razem moc $288 \mathrm{~kW}$ i średnie natężenie oświetlenia na poziomie około 100 lx. 
Podczas modernizacji w hali zastosowane zostały 192 oprawy w technologii LED typu ILO3M100E12PW o mocy $100 \mathrm{~W}$, tak więc moc systemu oświetleniowego została zredukowana do poziomu około $20 \mathrm{~kW}$, co nawet przy założeniu pracy z mocą znamionową daje ponad dziesięciokrotnie mniejsze zapotrzebowanie na energię. Zastosowanie nowoczesnych opraw w technologii LED oprócz zmniejszenia zużycia energii elektrycznej przyniosło także korzyść w postaci poprawy warunków oświetleniowych we wnętrzu hali. Oprawy zamontowano na wysokości $7,5 \mathrm{~m}$, płaszczyzna pracy wzrokowej zdefiniowana została na wysokości $0,85 \mathrm{~m} \mathrm{z}$ marginesem $1,5 \mathrm{~m}$. Rozkład natężenia oświetlenia na płaszczyźnie pracy przedstawia rys. 5.

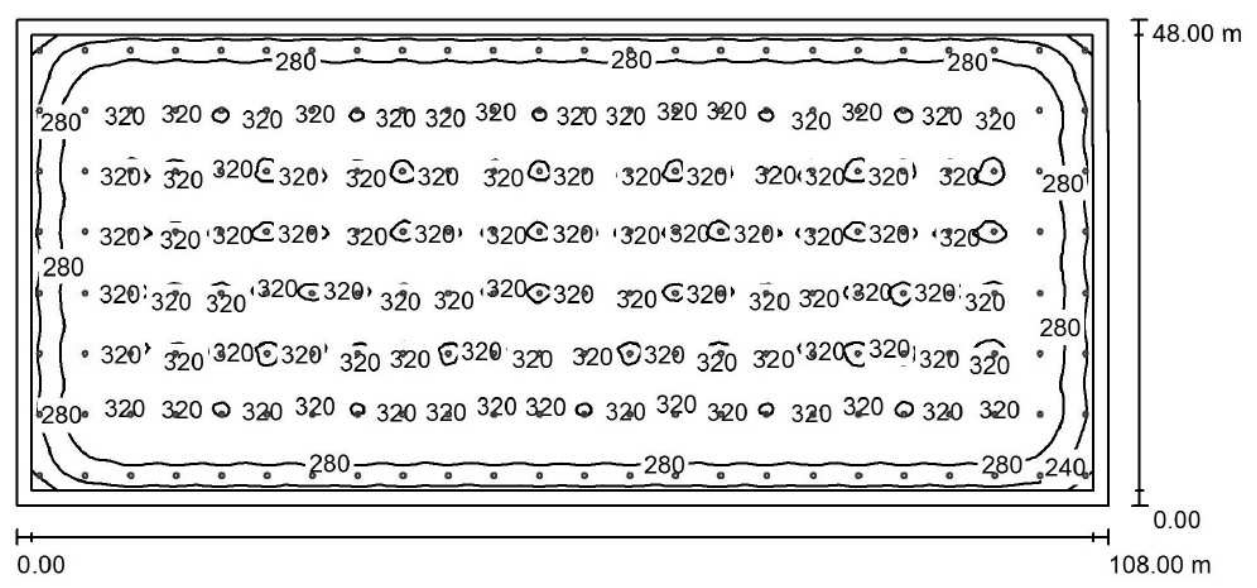

Rys. 5. Rozkład natężenia oświetlenia w hali po modernizacji [5]

Fig. 5. The distribution of light intensity in the hall after modernization [5]

Jak można zauważyć, rozkład izoluksów jest dość równomierny, co przekłada się na zapewnienie komfortu pracy wzrokowej. Średnie natężenie oświetlenia wynosi 302 lx (tab. 2), czyli trzy razy więcej, niż przed modernizacją.

Tabela 2. Wartości średnie, minimalne i maksymalne natężenia oświetlenia na płaszczyznach pomieszczenia [5]

Table 2. Illuminance values on the work plane: average, minimum and maximum [5]

\begin{tabular}{|c|c|c|c|c|c|}
\hline Powierzchnia & $\boldsymbol{\rho}[\boldsymbol{\%}]$ & $\mathbf{E}_{\mathbf{m}}[\mathbf{l x}]$ & $\mathbf{E}_{\mathbf{m i n}}[\mathbf{l x}]$ & $\mathbf{E}_{\mathbf{m a x}}[\mathbf{l x}]$ & $\mathbf{E}_{\mathbf{m i n}} / \mathbf{E}_{\mathbf{m a x}}[\mathbf{l x}]$ \\
\hline Płaszczyzna pracy & $/$ & 302 & 173 & 324 & 0,571 \\
\hline Podłoga & 10 & 289 & 106 & 322 & 0,367 \\
\hline Sufit & 20 & 26 & 17 & 30 & 0,661 \\
\hline Ściany (4) & 26 & 74 & 12 & 206 & $/$ \\
\hline
\end{tabular}


Oprawy pracują pod kontrolą systemu sterowania oświetleniem BS-DALI-1, wobec czego poziom natężenia oświetlenia we wnętrzu jest regulowany w zależności od warunków oświetlenia dziennego. Dzięki temu przy słonecznej pogodzie możliwe jest ściemnienie opraw w strefie przyokiennej, przy zachowaniu wymaganego poziomu natężenia oświetlenia. Praca w trybie adaptacyjnym pozwala na dalsze ograniczenie ilości energii elektrycznej zużywanej do oświetlenia obiektu.

\section{Podsumowanie}

Przedstawiony $\mathrm{w}$ artykule adaptacyjny system sterowania oświetleniem wykorzystujący wydajne oprawy w technologii LED oraz dostosowujący poziom natężenia oświetlenia do warunków oświetlenia dziennego jest nowoczesnym rozwiązaniem, które pozwala na znaczne ograniczenie zużycia energii, a przez to zmniejszenie kosztów eksploatacji instalacji oświetleniowej, co ma istotne znaczenie w obiektach przemysłowych, ze względu na dużą liczbę pracujących opraw. Ponadto stosowanie wydajnych przemysłowych opraw ze źródłami LED pozwala nie tylko ograniczyć zużycie energii, ale także zmniejszyć liczbę stosowanych opraw, co ma znaczenie dla kosztów inwestycji. Niewątpliwą zaletą systemu adaptacyjnego jest także łatwość jego rozbudowy i modyfikacji elementów jak również sposobu jego działania i dostosowania do specyficznych potrzeb użytkownika.

\section{Literatura}

[1] www.automatykab2b.pl - DALI - światło ujarzmione [data dostępu 30.04.2014].

[2] www.dali-ag.org - strona internetowa systemu DALI [data dostępu 30.04.2014].

[3] www.solls.pl/pl/przemysłowe/ ILO3M30-300 _data.pdf - Karta katalogowa, Oświetlenie przemysłowe LED SOLLS ILO3M30-300 [data dostępu 15.05.2014].

[4] PN-90/E-01005 Technika świetlna. Terminologia, Wydawnictwa Normalizacyjne Warszawa 1991.

[5] www.solls.pl/pl /realizacje/hsw_podsumowanie.pdf - Podsumowanie realizacji modernizacji oświetlenia przykładowej hali, In4Poland Sp. z o.o. [data dostępu 10.05.2014].

[6] www.solls.pl/pl/sterowanie/BS-ST-DIN-DALI.pdf - System oświetleniowy SOLLS BS-ST-DIN-DALI, Dokumentacja techniczno-ruchowa [data dostępu 15.05.2014].

[7] www.solls.pl/images/led_solls_hala_sw3-4.jpg - materiały fotograficzne z realizacji [data dostępu 15.05.2014].

[8] www.swiatlo.com - System sterowania DALI [data dostępu 30.04.2014].

[9] Władziński W.: Inteligentne sterowanie oświetleniem w budynkach przemysłowych. Zeszyty Naukowe Wydziału Elektrotechniki i Automatyki Politechniki Gdańskiej, nr 20, 2004, s. 211-216. 
[10] Żagan W.: Podstawy techniki świetlnej. Oficyna Wydawnicza Politechniki Warszawskiej, Warszawa 2005.

\section{INDUSTRIAL APPLICATIONS OF ADAPTIVE LIGHTING SYSTEMS BASED ON LED TECHNOLOGY}

\section{S u m m a r y}

In industrial building objects, for example production halls, magazines, a role of the lighting is particularly important to provide appropriate visual work conditions. In large halls, where occur big window surfaces for optimal utilization of natural light, there appears a problem of artificial light and daylight cooperation, which causes irregular distribution of illuminance near windows. In this paper there is shown a practical implementation of adaptive lighting system, based on LED technology and DALI system. The example bases on production hall. An analysis of presented application advantages was processed.

The discussed system is designed for dynamic lighting control in industrial or office objects, where is needed illuminance regulation according to daylight conditions or division lighting system for some specified areas. In presented object during modernization 720 mercury lamps was replaced by 192 LED luminaires. It caused an improvement of lighting conditions and reduction of energy consumption of light sources.

The adaptive lighting system shown in this paper, which uses high efficient LED luminaires and adjusting illuminance level for daylight conditions is a modern solution. It allows for significant energy consumption reduction, hence utilization costs decrease of illuminating installation, which is really important in industrial objects, in view of amount of used luminaires.

Keywords: adaptive lighting, LED lamp, DALI system, energy efficiency

Przestano do redakcji: $22.10 .2015 \mathrm{r}$.

Przyjęto do druku: $30.10 .2015 \mathrm{r}$.

DOI:10.7862/rb.2015.111 